\title{
Old wine in new bottles
}

\section{An agenda for biology that's in its second century — and still going strong.}

\section{Jane Maienschein}

(6) he magnitude of the problem of development, whether ontogenetic or phylogenetic, has been underestimated," wrote Edmund Beecher Wilson. "Yet the splendid achievements of cell-research in the past twenty years showed us the promise of the possibilities for the future."

Wilson rejected both the theorists' claims to have answered the important questions about life and the vitalists' insistence that we can never answer them with materialistic science. He insisted that through experimental research, "step by step the way may yet be opened to an understanding of inheritance and development". The quotations are from The Cell in Development and Inheritance, published in 1896. Wilson's emphasis on a balanced study of all aspects of living organisms remains as compelling today, and reminds us of the value of studying the history of biology as well as of organic life.

In three books published during 1895-96, Wilson addressed what today we call biocomplexity. His positivistic programme for scientific progress was grounded in epistemology, epigenesis, evolution and education.

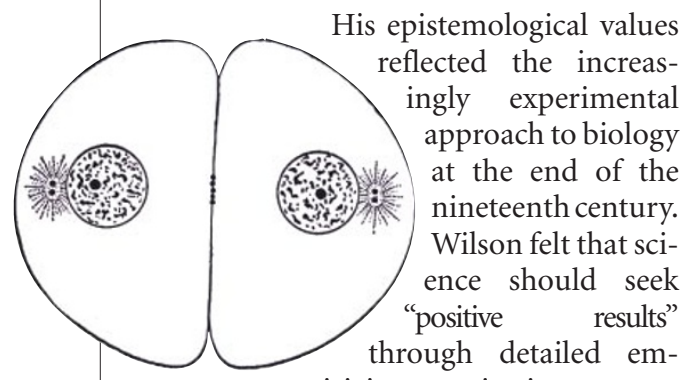

piricism, rejecting metaphysics. The first published photographs of cell division appeared in Wilson's 1895 An Atlas of the Fertilization and Karyokineses of the Ovum. He felt that, as an eyewitness account, they provided compelling evidence about cell structures. Such carefully discovered details then led to empirical generalizations, in turn the grounds for new hypotheses.

But the process of turning observation into general principles and theory does not immediately give a perfect reflection of nature. Further, it takes us "beyond the solid ground of fact into a region of more or less doubtful and shifting hypothesis, where the point of view continually changes as we proceed". Yet he held that science is not just speculation, and working hypotheses guide us beyond a collection of facts to an under-

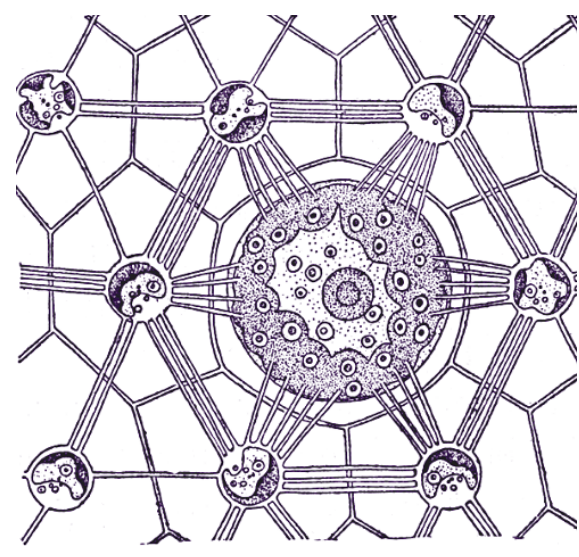

standing of organizing principles and testable theory. Few modern scientists would disagree.

For Wilson, development was not chaotic, as it begins with inherited chromosomes in the nucleus and inherited cytoplasmic structure. Inheritance guides development, which is capable (more or less, because of past evolutionary adaptations) of responding to environmental conditions. The cell binds inheritance and development, and provides the first of two foundations for biology.

Unlike some today,

Wilson had a balanced view of life, with neither too much free will in the form of regulatory plasticity, nor too much genetic determinism. Heredity and development must work together, and always in the context of an evolutionary past. Wilson saw the organism as an assemblage of responsive, vital and integrated interdependent parts, and he saw biology as seeking an understanding of all life within one research programme. He was sure that by progressing 'step by step' we can understand the principles driving even the most fundamental life processes. But someone has to integrate the steps and the pieces, as the organism functions and lives as a whole. That is the fine wine of biocomplexity.

Evolution provided Wilson's other foundation for life, and for biology. History is therefore fundamental for biology. All life has evolved and carries responses to past conditions. For the most part, however, evolutionary processes lie in the past, and experimental biologists need not consider evolution directly when studying cells, development and inheritance. Yet evolution is an essential background condition that scientists ignore at their peril.

Education is important both for researchers and for a wider public understanding. Wilson and his cousin William Sedgwick published the second edition of their General Biology in 1896. They sought to promote understanding of the principles of life, starting with fundamental patterns and processes and working up to the complexities of living, functioning, growing, differentiating and reproducing higher organisms. Although beginning with simple examples, Wilson and Sedgwick insisted that life is more than the sum of its mutually interdependent parts and that the organism acts as a living whole.

Wilson outlined a biology programme for his time, and for ours. As every egg contains its past, present and future, Wilson's unified view provides an early 'evo-devocellulo' approach to biology. His contributions remind us that life - and the science that studies it - "can best be appreciated from an historical point of view". The history of science helps us appreciate the old wine, and our growing understanding of biology through the historical events of evolution, inheritance and development provides the new bottles.

Jane Maienschein is in the Department of Philosophy, Arizona State University,

Tempe, Arizona 85287-2004, USA.

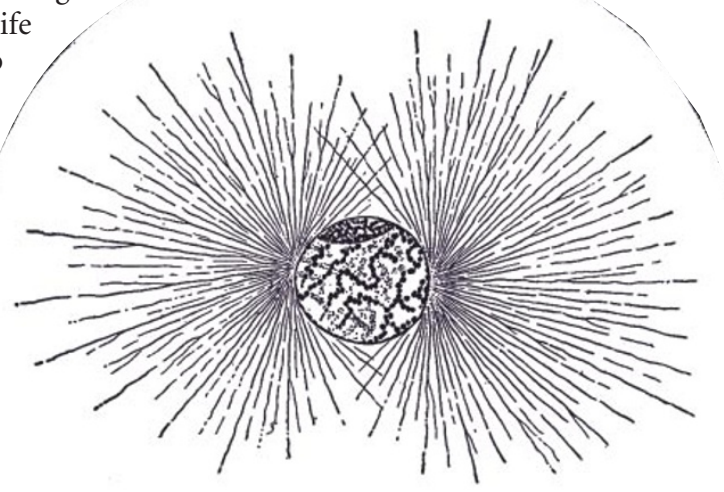

